\title{
Urinary Tract Infection Profile at the Clinic of Infectious and Tropical Diseases at Fann University Hospital, Dakar, Senegal
}

\author{
Lakhe NA ${ }^{1^{*}}$, Diallo Mbaye $K^{1}$, Sylla $K^{2}$, Dia $\mathbf{M L}^{3}$, Dia Badiane $\mathbf{N M}^{4}$, Ndiaye $\mathbf{R}^{1}$, Cisse Diallo VMP ${ }^{1}$, Ka $\mathbf{D}^{1}$, Fortes Deguenonvo $\mathrm{L}^{1}$, Ndour $\mathbf{C T}^{1}$, Soumare $\mathbf{M}^{1}$ and \\ Seydi $\mathbf{M}^{1}$ \\ ${ }^{1}$ Clinic of Infectious and Tropical Diseases, Fann National University Hospital, Fann, Dakar, Senegal \\ ${ }^{2}$ Parasitology-Mycology Service, Faculty of Medicine, Cheikh Anta Diop University, Fann, Dakar, Senegal \\ ${ }^{3}$ Bacteriology Laboratory, Fann National University Hospital, Dakar, Senegal \\ ${ }^{4}$ Department of Infectious Diseases, Gaston Berger University, Saint-Louis, Senegal
}

*Corresponding author: Lakhe NA, Clinic of Infectious and Tropical Diseases, Fann National University Hospital, 5035-Fann, Dakar, Senegal, Tel: +221775417301; Email: aissatou.lakhe@ucad.edu.sn

Received date: June 14, 2018; Accepted date: July 16, 2018; Published date: July 23, 2018

Copyright: $\odot 2018$ Lakhe NA, et al. This is an open-access article distributed under the terms of the Creative Commons Attribution License, which permits unrestricted use, distribution, and reproduction in any medium, provided the original author and source are credited.

\begin{abstract}
Objective: The objectives of this study were to describe epidemiological, clinical and bacteriological profile of the UTIs diagnosed at the infectious diseases Clinic of Fann University Hospital in Dakar and to determine their antibiotic resistance patterns.
\end{abstract}

Methods: A descriptive and retrospective study was conducted from January 1, 2013 to December 31, 2014 and based on inpatient records for infectious and tropical diseases, collected. Clean-catch midstream urine was collected and analyzed using standard microbiological procedures. Antibiogram was done by disc diffusion method.

Results: Of the 1922 hospitalized patients, 98 (5.1\%) developed UTIs. Among these, 58 (59.2\%) were males and 40 were females (sex ratio $=1.45$ ). Urinary tract infection was most commonly found in the age group 30-44 years $(36.7 \%)$. HIV was the main comorbidity with 65 cases $(77.4 \%)$. A urinary catheter was present in 21 patients $(21.4 \%)$. Samples were monomicrobial in 78 cases $(79.6 \%)$. A total of 117 bacterial strains were isolated, including $94(80.3 \%)$ for Gram-negative bacilli. Among these strains, the most common uropathogens isolated were Klebsiella pneumoniae (34 strains, 29.1\%) and Escherichia coli (33 strains, 28.2\%). The overall antimicrobial resistance of the main isolates was very high regarding amoxicillin-clavulanate, third generation cephalosporin, ciprofloxacin and trimethoprim-sulfamethoxazole with resistance rate of $48 \%, 30.4 \%, 48.8 \%$ and $46 \%$, respectively. Half of the patients received probabilistic treatment. In mono antibiotic therapy, the mostly used antibiotic was ceftriaxone $(88.2 \%)$ while in combination, it was amoxicillin-clavulanate $(47.1 \%)$ followed by ceftriaxone $(41.3 \%)$.

Conclusion: UTIs appear to be frequent in our service. Strategies for the reduction for these UTIs must be implemented, mainly through the coding of UTls, urinary catheter placement and monitoring protocols and continuous surveillance. Also, the recommendation of treatment should be reviewed.

Keywords: Urinary tract infection; Hospital; Inpatients; Infectious diseases; Senegal

\section{Introduction}

Urinary tract infections (UTIs) are a serious public health problem in terms of morbidity and financial cost, with about 150 million cases per year worldwide, costing the world economy more than 6 billion USD [1]. They are a common reason for consultation in both the community and the health care facilities [2-5].

UTIs are also one of the most common nosocomial infection especially catheter-associated urinary tract infection (CAUTI) [3,6,7]. Prevalence of healthcare-associated urinary tract an infection (HAUTIs) among healthcare-associated infections vary according to geographical location and is $12.9 \%, 19.6 \%$ and $24 \%$ in the United States, Europe and developing countries, respectively [3]. In the United States, a recent study reports that UTIs are the fourth most common health care-associated infection and two-thirds are catheter associated
[8]. The frequency and severity of these conditions justify the high number of dedicated studies around the world. Urinary tract infections can affect patients regardless their age or gender but with predominance in women [3-5,9].

Some factors such as diabetes, pregnancy, immunocompromised conditions, indwelling urinary catheters, renal failure or hospitalacquired infection are associated with complicated urinary tract infections [2]. These factors increase the risk of recurrent infections or treatment failure.

Gram-negative bacteria, specifically Enterobacteriaceae, are common causes of both CAUTI and HAUTI [2,3]. Escherichia coli is the strains which is mostly responsible $[2-6,9,10]$. However, other uropathogenic strains are emerging and are commonly involved in HAUTIs or complicated UTIs. These are Klebsiella pneumonia, Acinetobacter spp, coagulase negative Staphylococci, Staphylococcus aureus and Pseudomonas spp [3,8,11-14]. 
Due to their high prevalence and their increase in nosocomial infections, UTIs motivate a high number and sometimes inappropriate prescription of antibiotics [2]. This explain the high level of resistance of germs isolated during urinary infections to the mostly used antibiotics such as amoxicillin or amoxicillin clavulanic acid, cotrimoxazole, ciprofloxacin and third generation cephalosporins $[2,6,12,15]$. Therefore, in the current era of high-resistance rates toward antibiotics, it is essential to be aware of the epidemiological data for an appropriate initial treatment [3].

Within the facility of the Fann National University Hospital Center, urinary tract infections are the most common care-associated infection [16]. Also, in this hospital, the Clinic of Infectious and Tropical Diseases was the second largest provider of urinary tract infections [17]. To-date, no study has focused specifically on urinary tract infections in this health care unit.

In this context, we carried out this study which main objective was to perform an analysis of urinary tract infections diagnosed at the infectious diseases Clinic of Fann University Hospital in Dakar. The specific objectives were to describe epidemiological, clinical and bacteriological profile of these infections and to determine the antibiotic resistance patterns of bacterial isolates.

\section{Materials and Methods}

Our study was conducted at the Clinic of Infectious and Tropical Diseases of the Fann University Hospital in Dakar. This was a descriptive and retrospective study based on inpatient records for infectious and tropical diseases, collected over a 24-month period from January 1, 2013 to December 31, 2014. All the patients, regardless of sex or age, diagnosed with urinary tract infection were included in this study.

The diagnosis of a urinary tract infection was made through the cytobacteriological examination of urine (ECBU) followed by an antibiogram. Urinary tract infection was defined as bacteriuria $\geq 105$ $\mathrm{cfu} / \mathrm{ml}$ of urine, leukocyturia $\geq 104 / \mathrm{ml}$ of urine in patients with mainly usual cystitis signs. Each urine sample collected from hospitalized patients was subjected to routine cytobacteriological examination of urine including macroscopic examination, fresh examination to assess leukocyturia, staining of Gram and culture on Cystine-Lactose-Electrolyte-Deficient (CLED) medium with enumeration of germs. The identification was made by a conventional biochemical gallery in tubes supplemented as needed by an Api 20E gallery (Bio Mérieux). Once the identification of the germs was done according to conventional techniques, each isolate was subjected to a standard antibiogram by the method of diffusion of the antibiotic discs in agar medium Mueller Hinton $(\mathrm{MH})$ in accordance with the recommendations of the Antibiogram Committee of the French Society of Microbiology (CASFM). To simplify the interpretation of the phenotypes of resistance, intermediate categorized strains were considered resistant.

Data were collected from patients' records. A standard survey form was completed for each patient that had helped to collect demographic data (age, sex, geographical origin, occupation, marital status); clinical data (HIV status, reasons for admission, origin of infection, associated diagnosis); bacteriological data (isolated germs, bacterial resistance, mono or poly microbial culture); biological data (NFS, CRP, renal function, glycemia); therapeutic data (antibiotics used, duration of treatment, association or not); prognostic data (time and duration of hospitalization, evolutionary modalities).
Data entry was done using Epi-Data software version 3.5.1 and their analysis was carried out using Stata/SE software version 12.1. Categorical variables were expressed in terms of frequency and percentage of data entered with $95 \%$ confidence intervals (CI) assuming a Poisson distribution. Quantitative variables were expressed in means \pm standard deviation or median (IQR) according to their conditions of applicability.

\section{Results}

During the study period of the 1922 hospitalized patients, 98 cases of urinary tract infections were collected, (i.e. a prevalence of $5.1 \%$ ). Urinary tract infections accounted for $36.8 \%$ (98/266) of diagnosed bacterial infections.

\section{Demographic characteristics}

The demographic characteristics of the study population are shown in Table 1. Among the 98 cases of UTIs, 58 (59.2\%) were males and 40 females (sex ratio=1.45).

\begin{tabular}{|c|c|c|c|}
\hline $\begin{array}{l}\text { Demographic } \\
\text { characteristics }\end{array}$ & Frequency (No.) & Percentage (\%) & $95 \% \mathrm{Cl}$ \\
\hline \multicolumn{4}{|l|}{ Sex } \\
\hline Male & 58 & 59.2 & $44.9-76.5$ \\
\hline Female & 40 & 40.8 & $29.2-55.6$ \\
\hline \multicolumn{4}{|c|}{ Age group (years) } \\
\hline $14-29$ & 17 & 17.3 & 10.1-27.8 \\
\hline $30-44$ & 40 & 40.8 & $29.2-55.6$ \\
\hline $45-59$ & 20 & 20.4 & $12.5-31.5$ \\
\hline $60-74$ & 13 & 13.3 & $7.1-22.7$ \\
\hline$>75$ & 8 & 8.2 & $3.5-16.1$ \\
\hline \multicolumn{4}{|c|}{ Geographic origin } \\
\hline Urban & 39 & 39.8 & 28.3-54.4 \\
\hline Suburban & 47 & 48 & $35.2-63.8$ \\
\hline Rural & 12 & 12.2 & $6.3-21.4$ \\
\hline \multicolumn{4}{|l|}{ Marital status } \\
\hline Married & 40 & 40.8 & $29.2-55.6$ \\
\hline Single & 16 & 16.3 & $9.3-26.5$ \\
\hline Divorced & 9 & 9.2 & $4.2-17.4$ \\
\hline Widower & 5 & 5.1 & $1.7-11.9$ \\
\hline Unknown & 28 & 28.6 & $19-41.3$ \\
\hline
\end{tabular}

Shows the demographic characteristics of UTIs $(\mathrm{N}=98)$ with predominance of males $(59.2 \%)$, age group $30-44$ years $(36.7 \%)$ and married patients $(40.8 \%)$.

Table 1: Demographic characteristics of patients presenting UTI at the Infectious and Tropical Diseases in Dakar from 2013 to 2014.

The average age of the study population was 42 [IQR, 32-57] ranging from 12 to 92 years. Urinary tract infection was most 
Citation: Lakhe NA, Mbaye KD, Sylla K, Dia ML, Badiane NMD, et al. (2018) Urinary Tract Infection Profile at the Clinic of Infectious and Tropical Diseases at Fann University Hospital, Dakar, Senegal. J Antimicrob Agents 4: 174. doi:10.4172/2472-1212.1000174

Page 3 of 8

commonly found in the age group 30-44 years (36.7\%). Nearly half of the patients came from the suburban area $(47.9 \%)$ and 39 patients came from the urban area (39.8\%). Regarding marital status, it was specified in 70 patients, most of whom were often married (40 cases) or divorced (16 cases).

\section{Clinical aspects}

Comorbidity was found in 84 cases.

The main comorbidities were HIV infection (65 cases 77.4\%), alcoholism (11 cases), high blood pressure (9 cases) and diabetes (4 cases). Fourteen patients had no comorbidity (14.3\%).

Regarding the profile of $65 \mathrm{HIV}$-infected patients, sixty-one (93.8\%) were HIV-1, three (4.6\%) HIV-2, and one double-profile patient (1.5\%). The main reasons for hospitalization were sepsis $(74.5 \%)$, general impairment $(32.7 \%)$ and pulmonary condensation $(32.7 \%)$. Urinary burning was found in only one out of the 98 cases (1\%). A total of 52 patients had a diagnosis associated with urinary tract infection.

The main associated diagnosis was tuberculosis in 20 cases (38.5\%) and neuromeningeal infections in 12 cases $(23.1 \%)$. A urinary catheter was present in 21 patients (21.4\%).

\section{Biological aspects}

More than half of the patients with urinary tract infection (57.1\%) had a level of hemoglobin between 8 and $12 \mathrm{~g} / \mathrm{dL}$ and the mean hemoglobin level was $8.9 \pm 2.5 \mathrm{~g} / \mathrm{dL}$. For white blood cells, the average rate was $8887.95 \pm 8618 / \mathrm{mm}^{3}$. Most patients $(58.3 \%)$ had globules between 4000 and $10000 / \mathrm{mm}^{3}$. For neutrophils, $55 \%$ of patients had a number between 1600 and $4000 / \mathrm{mm}^{3}$. More than 2 out of $3(68.9 \%)$ patients had lymphocytes less than $1500 / \mathrm{mm}^{3}$. Regarding the C reactive protein (CRP), the average level was $83.1 \pm 57.2 \mathrm{mg} / \mathrm{L}$. More than half of the patients (54.5\%) had a level between 48 and $96 \mathrm{mg} / \mathrm{L}$. When it comes to glycaemia, the average rate was $0.96 \pm 0.26 \mathrm{~g} / \mathrm{L}$. Four patients $(11.8 \%)$ had a rate greater than or equal to $1.26 \mathrm{~g} / \mathrm{L}$. The average serum creatinine was $14.5 \pm 16.2 \mathrm{mg} / \mathrm{L}$. Nearly 8 out of 10 patients $(79.1 \%)$ had normal serum creatinine.

\section{Bacteriological aspects}

Samples were monomicrobial in 78 cases $(79.6 \%)$ and polymicrobial in 20 cases $(20.4 \%)$. A total of 117 bacterial strains were isolated, including $94(80.3 \%)$ for Gram-negative bacilli and 23 (19.7\%) for Gram-positive bacilli. Among these strains, the main bacterial species isolated were Klebsiella pneumoniae (34 strains, 29.1\%), Escherichia coli (33 strains, $28.2 \%)$.

These species were followed by Acinetobacter sp, Enterobacter sp and Staphylococcus aureus with 7 strains for each of these 3 species. Other bacterial species were isolated but to a lesser extent. Among the 20 polymicrobial samples, Klebsiella pneumoniae was found in the 13 .

Isolated Escherichia coli strains had high levels of resistance for amoxicillin-clavulanate (60.6\%), ciprofloxacin (57.6\%) and third generation cephalosporin (42.4\%). Resistance was low in the order of $3 \%$ for imipenem and colistin. Concerning the strains of Klebsiella pneumoniae, resistance was high to amoxicillin-clavulanic acid (82.4\%), ciprofloxacin (73.5\%), cotrimoxazole (61.8\%) and third generation cephalosporin $(41.2 \%)$. It was low for gentamicin $(2.9 \%)$ and imipenem (2.9).

The results of the studies are highlighted and illustrated in Tables $2-7$.

\begin{tabular}{|c|c|c|c|}
\hline Clinical aspects & Frequency (n) & Percentage (\%) & $95 \% \mathrm{Cl}$ \\
\hline \multicolumn{4}{|l|}{ Comorbidity } \\
\hline HIV & 65 & 66.3 & $51.2 \_84.5$ \\
\hline Alcohol abuse & 11 & 11.2 & 5.6_20.1 \\
\hline High blood pressure & 9 & 9.2 & $4.2-17.4$ \\
\hline Diabetes & 4 & 4.1 & $1.1-10.5$ \\
\hline Hepatitis B & 2 & 2 & $0.2-7.4$ \\
\hline Strokes & 2 & 2 & $0.2-7.4$ \\
\hline Obesity & 1 & 1 & $0.02-5.7$ \\
\hline Prostate adenectomy & 1 & 1 & $0.02-5.7$ \\
\hline No comorbidity & 14 & 14.3 & $7.8-24$ \\
\hline \multicolumn{4}{|c|}{ Clinical signs or syndrome } \\
\hline Sepsis & 76 & 74.5 & $61.1-97.1$ \\
\hline General impairment & 32 & 32.7 & $22.3-46.1$ \\
\hline $\begin{array}{l}\text { Pulmonary } \\
\text { condensation }\end{array}$ & 32 & 32.7 & $22.3-46.1$ \\
\hline Lower back pain & 32 & 32.7 & $22.3-46.1$ \\
\hline Febrile Diarrhea & 30 & 30.6 & $20.7-43.7$ \\
\hline Immunodeficiency & 21 & 21.4 & $13.3-32.8$ \\
\hline $\begin{array}{l}\text { Impaired } \\
\text { consciousness }\end{array}$ & 19 & 19.4 & $11.7-30.3$ \\
\hline Burning during urination & 1 & 1 & $0.02-5.7$ \\
\hline \multicolumn{4}{|l|}{ Associated diagnosis } \\
\hline Tuberculosis & 20 & 38.5 & $23.5-59.4$ \\
\hline $\begin{array}{l}\text { Neuromeningeal } \\
\text { infections }\end{array}$ & 12 & 23.1 & $11.9-40.3$ \\
\hline Pneumonia & 5 & 9.6 & $3.1-22.4$ \\
\hline Renal failure & 5 & 9.6 & $3.1-22.4$ \\
\hline Tetanus & 4 & 7.7 & $2.1-19.7$ \\
\hline Gastroenteritis & 2 & 3.8 & $0.5-13.9$ \\
\hline Malaria & 1 & 1.9 & $0.1-10.7$ \\
\hline Cryptosporidiosis & 1 & 1.9 & $0.1-10.7$ \\
\hline Ovarian tumor & 1 & 1.9 & $0.1-10.7$ \\
\hline Kaposi's sarcoma & 1 & 1.9 & $0.1-10.7$ \\
\hline \multicolumn{4}{|l|}{ Urinary catheter } \\
\hline Yes & 21 & 21.4 & $13.3-32.8$ \\
\hline
\end{tabular}


Citation: Lakhe NA, Mbaye KD, Sylla K, Dia ML, Badiane NMD, et al. (2018) Urinary Tract Infection Profile at the Clinic of Infectious and Tropical Diseases at Fann University Hospital, Dakar, Senegal. J Antimicrob Agents 4: 174. doi:10.4172/2472-1212.1000174

Page 4 of 8

\begin{tabular}{|l|l|l|l|}
\hline No & 77 & 78.6 & $62-98.2$ \\
\hline
\end{tabular}

Table 2: Comorbidity, clinicals signs and associated diagnosis of patients presenting UTI at the Infectious and Tropical Diseases in Dakar from 2013 to 2014.

\begin{tabular}{|c|c|c|}
\hline Biological parameters & Frequency no. (\%) & $95 \% \mathrm{Cl}$ \\
\hline \multicolumn{3}{|l|}{ Hemoglobin (g/dL) } \\
\hline$<8$ & $32 / 98(32.7)$ & $22.3-46.1$ \\
\hline 12-Aug & $59 / 98(60.2)$ & $45.8-77.7$ \\
\hline$>12$ & 7/98 (7.1) & $2.9-14.7$ \\
\hline \multicolumn{3}{|c|}{ White blood cells $\left(\mathrm{cel} / \mathrm{mm}^{3}\right.$ ) } \\
\hline$<4000$ & 22/98 (22.4) & $14.1-34$ \\
\hline $4000-12000$ & $58 / 98(59.2)$ & $44.9-76.5$ \\
\hline$>12000$ & 18/98 (18.4) & $10.8-29$ \\
\hline \multicolumn{3}{|l|}{ Neutrophils $\left(/ \mathrm{mm}^{3}\right)$} \\
\hline$<1500$ & 15/90 (16.7) & $9.3-27.5$ \\
\hline $1500-7000$ & $52 / 90(57.8)$ & $43.1-75.8$ \\
\hline$>7000$ & $23 / 90(25.5)$ & $16.2-38.3$ \\
\hline \multicolumn{3}{|l|}{ Lymphocytes $\left(/ \mathrm{mm}^{3}\right)$} \\
\hline$<1500$ & 66/95 (69.5) & $53.7-88.4$ \\
\hline $1500-4000$ & 23/95 (24.2) & $15.3-36.3$ \\
\hline$>4000$ & 6/95 (6.3) & $2.3-13.7$ \\
\hline \multicolumn{3}{|l|}{ CRP (mg/L) } \\
\hline$<6$ & 7/92 (7.6) & $3-15.7$ \\
\hline $6-47$ & $14 / 92(15.2)$ & $8.3-25.5$ \\
\hline 48-96 & $57 / 92(62)$ & $46.9-80.3$ \\
\hline$>96$ & 14/92 (15.2) & $8.3-25.5$ \\
\hline \multicolumn{3}{|l|}{ Glycemia (g/L) } \\
\hline$<1.26$ & $61 / 72(84.7)$ & $64.8-100$ \\
\hline$\geq 1.26$ & $11 / 72(15.3)$ & $7.6-27.3$ \\
\hline \multicolumn{3}{|l|}{ Creatinine (mg/L) } \\
\hline$<13$ & $14 / 18(77.8)$ & $42.5-100$ \\
\hline $13-30$ & $1 / 18(5.5)$ & $0.1-30.9$ \\
\hline$>30$ & $3 / 18(16.7)$ & $3.4-48.7$ \\
\hline \multicolumn{3}{|c|}{$\begin{array}{l}\text { Represents blood examination results of patients with UTIs }(\mathrm{N}=98) \text { with a } \\
\text { majority of anemia }(91 / 98) \text {, a lymphopenia in } 66 \text { patients and elevated } C R P>48 \\
\mathrm{mg} / \mathrm{L} \text { in } 73 / 92 \text { patients. }\end{array}$} \\
\hline
\end{tabular}

Table 3: Distribution according to biological parameters of patients presenting UTI at infectious and tropical Disease Clinic in Dakar from 2013 to 2014.
Bacterial isolates are listed in Table 4. A total of 117 isolates were found with a majority of Gram-negative bacilli (94 i.e. $80.3 \%$ ). Most common uropathogens were Klebsiella pneumoniae (34 isolates) and Escherichia coli (33 isolates).

\begin{tabular}{|l|l|l|l|}
\hline Isolated bacterial strains & $\begin{array}{l}\text { Frequency } \\
\text { (No.) }\end{array}$ & $\begin{array}{l}\text { Percentage } \\
\text { (\%) }\end{array}$ & $\mathbf{9 5 \% ~ C l}$ \\
\hline Klebsiella pneumoniae & 34 & 29.1 & $20.1-40.6$ \\
\hline Escherichia coli & 33 & 28.2 & $19.4-39.6$ \\
\hline Acinetobacter sp & 7 & 6 & $2.4-12.3$ \\
\hline Enterobacter sp & 7 & 6 & $2.4-12.3$ \\
\hline Staphylococcus aureus & 7 & 6 & $2.4-12.3$ \\
\hline Pseudomonas sp & 6 & 5.1 & $1.9-11.1$ \\
\hline Staphylococcus saprophyticus & 6 & 5.1 & $1.9-11.1$ \\
\hline Streptocoque D & 5 & 4.3 & $1.4-10$ \\
\hline Proteus mirabilis & 3 & 2.6 & $0.5-7.5$ \\
\hline Streptocoque non groupable & 3 & 2.6 & $0.5-7.5$ \\
\hline Flavobacterium sp & 2 & 1.7 & $0.2-6.2$ \\
\hline Citrobacter sp & 1 & 0.9 & $0.1-4.7$ \\
\hline Providencia stuartii & 1 & 0.9 & $0.1-4.7$ \\
\hline Streptocoque B & 1 & 0.9 & $0.1-4.7$ \\
\hline Streptocoque G & 1 & 0.9 & $0.1-4.7$ \\
\hline Total & 117 & 100 & - \\
\hline
\end{tabular}

Table 4: Distribution of bacterial strains isolated in UTI at the Infectious and Tropical Diseases Clinic in Dakar from 2013 to 2014.

\begin{tabular}{|l|l|l|l|l|}
\hline \multirow{2}{*}{$\begin{array}{l}\text { Antibiotic } \\
\text { resistance }\end{array}$} & $\begin{array}{l}\text { Escherichia } \\
\text { coli }\end{array}$ & $\begin{array}{l}\text { Klebsiella } \\
\text { pneumoniae }\end{array}$ & $\begin{array}{l}\text { Enterobacter } \\
\text { spp }\end{array}$ & $\begin{array}{l}\text { Acinetobacter } \\
\text { spp }\end{array}$ \\
\cline { 2 - 5 } & $\mathrm{N}=33(\%)$ & $\mathrm{N}=34(\%)$ & $\mathrm{N}=7(\%)$ & $\mathrm{N}=7(\%)$ \\
\hline Amoxicillin & $19(57.6)$ & $22(64.7)$ & $3(42.9)$ & $1(14.3)$ \\
\hline $\begin{array}{l}\text { Amoxicillin- } \\
\text { clavulanate }\end{array}$ & $20(60.6)$ & $28(82.4)$ & $3(42.9)$ & $0(0)$ \\
\hline $\begin{array}{l}\text { Third generation } \\
\text { cephalosporin }\end{array}$ & $14(42.4)$ & $14(41.2)$ & $3(42.9)$ & $2(28.6)$ \\
\hline Ciprofloxacin & $19(57.6)$ & $26(73.5)$ & $5(71.4)$ & $2(28.6)$ \\
\hline Aztreonam & $11(33.3)$ & $14(41.2)$ & $2(28.6)$ & $0(0)$ \\
\hline Imipenem & $1(3)$ & $1(2.9)$ & $1(14.3)$ & $0(0)$ \\
\hline Piperacillin & $2(6.1)$ & $2(5.9)$ & $0(0)$ & $1(14.3)$ \\
\hline Kanamycine & $9(27.3)$ & $19(55.9)$ & $2(28.6)$ & $2(28.6)$ \\
\hline Gentamicine & $6(18.2)$ & $1(2.9)$ & $1(14.3)$ & $1(14.3)$ \\
\hline Cotrimoxazol & $15(45.5)$ & $21(61.8)$ & $2(28.6)$ & $1(14.3)$ \\
\hline
\end{tabular}


Citation: Lakhe NA, Mbaye KD, Sylla K, Dia ML, Badiane NMD, et al. (2018) Urinary Tract Infection Profile at the Clinic of Infectious and Tropical Diseases at Fann University Hospital, Dakar, Senegal. J Antimicrob Agents 4: 174. doi:10.4172/2472-1212.1000174

Page 5 of 8

\begin{tabular}{|l|l|l|l|l|}
\hline Colistin & $1(3)$ & $3(8.8)$ & $0(0)$ & $0(0)$ \\
\hline
\end{tabular}

Table 5: Antibiotic resistance of Escherichia coli, Klebsiella pneumoniae, Enterobacter sp and Acinetobacter sp isolated from UTI at the infectious Disease and Tropical clinic in Dakar from 2013 to 2014.

\begin{tabular}{|l|l|}
\hline Antibiotic resistance & Pseudomonas $\mathbf{N}=\mathbf{6}(\%)$ \\
\hline Amoxicillin & $0(0)$ \\
\hline Amoxicilline-acid clavulanate & $0(0)$ \\
\hline Ticarcillin & $1(16.7)$ \\
\hline Third generation cephalosporin & $0(0)$ \\
\hline Ciprofloxacin & $0(0)$ \\
\hline Aztreonam & $1(16.7)$ \\
\hline Imipenem & $1(16.7)$ \\
\hline Piperacillin & $0(0)$ \\
\hline Kanamycin & $2(33.3)$ \\
\hline Gentamicin & $0(0)$ \\
\hline Cotrimoxazol & $2(33.3)$ \\
\hline Colistin & $0(0)$ \\
\hline $\begin{array}{l}\text { Illustrates Pseudomonas isolates (n=6) antibiotic resistance. One of the strains } \\
\text { was resistant to imipenem. }\end{array}$ \\
\hline
\end{tabular}

Table 6: Antibiotic resistance of Pseudomonas sp isolated from UTI at the infectious Disease and Tropical clinic in Dakar from 2013 to 2014.

\begin{tabular}{|l|l|l|}
\hline \multirow{2}{*}{ Antibiotic resistance } & Staphylococcus & Streptococcus \\
\cline { 2 - 3 } & $\mathbf{N}=\mathbf{1 3}(\%)$ & $\mathbf{N}=10(\%)$ \\
\hline Amoxicillin-clavulanate & $0(0)$ & $0(0)$ \\
\hline Third generation cephalosporin & $1(7.7)$ & $7(70)$ \\
\hline Ciprofloxacin & $2(15.4)$ & $3(30)$ \\
\hline Imipenem & $1(7.7)$ & $1(10)$ \\
\hline Piperacillin & $0(0)$ & $0(0)$ \\
\hline Gentamicin & $3(23.1)$ & $7(70)$ \\
\hline Cotrimoxazol & $4(30.8)$ & $4(40)$ \\
\hline Oxacillin & $8(61.5)$ & $6(60)$ \\
\hline Lincomycin & $7(53.8)$ & $9(90)$ \\
\hline Erythromycin & $10(76.9)$ & $10(100)$ \\
\hline Fusidic acid & $0(0)$ & $2(20)$ \\
\hline Vancomycin & $0(0)$ & 0 \\
\hline
\end{tabular}

Shows antibiotic resistance of Staphylococci and Streptococci isolates. Staphylocci strains exhibit high resistance to oxacillin $(61.5 \%)$, erythromycin

$(76.9 \%)$ and cotrimoxazol (30.8) while Streptococci strains were all sensitive to amoxicillin-clavulanate.

Table 7: Distribution according to antibiotic resistance of Staphylococci and Streptococci during UTI in the Infectious and tropical Disease Clinic in Dakar from 2013-2014.

When it comes to the strains of Enterobacter, the resistance was high with ciprofloxacin (71.4\%), and of the order of $42.9 \%$ with amoxicillin-clavulanic acid and third generation cephalosporin. For the Acinetobacter strains, they showed complete sensitivity to amoxicillin-clavulanate, imipenem and aztreonam. Resistance was $28.6 \%$ to ciprofloxacin and third generation cephalosporin. Fosfomycin and pivmecillinam were not tested.

Antibiotic resistance of Escherichia coli, Klebsiella pneumoniae, Enterobacter sp and Acinetobacter sp isolated from UTIs is represented in Table 5.

Pseudomonas sp strains isolated in urine showed complete sensitivity to ciprofloxacin, third generation cephalosporin, gentamicin. One patient (16.7\%) had resistance to imipenem. See Table 6 for antibiotic resistance of Pseudomonas sp isolated strains. Isolated staphylococci strains showed high resistance to erythromycin (76.9\%), oxacillin (61.6\%), lincomycin (53.8\%) and pefloxacin (53.9\%).

Nearly two-third of isolated Staphylococcus aureus was resistant to methicillin (61.6\%). No resistance was found for vancomycin and fusidic acid (Table 7). Resistance to ciprofloxacin was around $15.4 \%$. Concerning isolated strains of streptococci, they were totally sensitive to amoxicillin-clavulanic acid, vancomycin and piperacillin. Significant resistance was found for lincomycin (90\%), gentamicin (70\%) and third generation cephalosporin (70\%). The resistance of Staphylococci and Streptococci for the different antibiotics tested is highlighted in Table 7.

\section{Therapeutic and pronostic aspects}

Forty-nine patients (50\%) received probabilistic antibiotic therapy. Their distribution was almost identical according to the number of antibiotics used. Thus, a mono or bi-antibiotic therapy was used in 17 patients respectively and in fifteen others, the number of antibiotics used was greater than 2 . In mono antibiotic therapy, the mostly used antibiotic was ceftriaxone (88.2\%). While in combination, the mostly used antibiotic was amoxicillin-clavulanic acid (47.1\%) followed by ceftriaxone (41.3\%).

Regarding the duration of antibiotic therapy, it was registered in 61 patients. In the latter, the average duration of antibiotic therapy was 9.8 \pm 8.5 days. Patients with duration of antibiotic therapy of less than 7 days were the more numerous (45.9\%), and more than a third $(37.7 \%)$ had duration of between 7 and 14 days.

The average length of stay in hospital was 18 days [range: 1-177]. Almost two-thirds (63.2\%) of patients were hospitalized for less than 21 days. More than a third of patients $(33.7 \%)$ with urinary tract infection died.

\section{Discussion}

Urinary tract infections (UTIs) are a major concern. The main objective of this study was to establish the profile of these infections at the Clinic of Infectious and Tropical Diseases of Fann University Hospital. The number of cases of urinary tract infections collected was 
98, a prevalence of $5.1 \%$. This rate is lower than those reported by some studies conducted in others resource-limited settings such as Mali, Côte d'Ivoire, Bhutan and Nepal with prevalence of $8.8 \%, 18.3 \%, 12.1 \%$ and $18.9 \%$ respectively. These differences could be explained by the short period of our study. However, during the same period, urinary tract infections accounted for over one third (36.8\%) of bacterial infections for which a pathogen had been isolated, regardless of the site of the infection. They occupy a prominent place in this health care unit and should be subject to surveillance $[10,18-20]$.

This study is also remarkable in terms of male predominance of urinary tract infections with $59.2 \%$ versus $40.8 \%$ in women, a sex ratio of 1.45 . On the contrary, most studies conducted around the world noted a female predominance of this type of infection [17,21]. Factors that would influence the high prevalence among women would be the proximity of the female urethral meatus of the anus, the short urethra of the woman, and sexual intercourse $[3,22,23]$.

Urinary tract infection can occur at any age in life. Nevertheless, there is a preponderance in young adults [5,21,24]. Our study corroborates this fact with these infections mostly found in the age group of 30-44 years. Nearly half of the study population (47.9\%) came from the suburban area. These figures can be explained by the fact that the Clinic of Infectious and Tropical Diseases is the reference service at the national level in this field. In addition, these populations have a low socio-economic status and have already been described as a risk factor for urinary tract infections [25].

In our study, comorbidity was found in 84 cases $(85.7 \%)$. The main one was HIV infection (66.3\%). This clinic is the reference center for HIV infected patients. The frequent association of urinary tract infections with HIV infection was also found previously [10,18]. The predominance of this specific population of people infected with HIV makes it possible to understand that the main associated diagnosis was tuberculosis and the main reasons for hospitalization in this study were sepsis (74.5\%), the deterioration of the general condition (32.7\%) and pulmonary condensation (32.7\%).

Of the 98 positive samples, 117 bacterial strains were isolated. Of these, Gram-negative Bacilli are the leading cause of urinary tract infections with 94 strains consistent with findings from previous studies $[3,25]$. The nosocomial origin or not of these infections was not specified in our study. The most frequently detected strains were Klebsiella pneumoniae (29.1\%), followed by Escherichia coli $(28.2 \%)$. Several studies have already demonstrated in the same country or elsewhere the prevalence of Escherichia coli in urinary tract infections $[2,3,9,17,23]$. Our study is remarkable for the large number of strains of Klebsiella pneumoniae, making it the most frequent pathogens before Escherichia coli. This would mainly reflect the nosocomial origin of these infections. Other bacteria of nosocomial origin were also found in our study, namely Acinetobacter sp and Enterobacter sp, which ranked third. All these elements indirectly show that healthcareassociated urinary tract infections (HAUTI) are a significant part of UTIs in our Clinic. The risk factors for the occurrence of HAUTI are multiple. Catheters are the major risk factor for hospital-acquired UTI $[3,26]$ and catheter placement increases the risk of UTI by four [26]. Every day that a urinary catheter is in place increases the risk of bacteriuria by $3 \%$ to $10 \%$ [23]. In our study, nearly one-quarter of patients with urinary tract infections had urinary catheters. This result is like the one in a recent survey conducted in different Australian hospitals with $26.3 \%$ of patients who had a urinary catheter at the time of the UTI-associated healthcare diagnosis (HAUTI) [27]. This important prevalence of catheter-associated infections in this service could be explained by the non-standardization of practices, the lack of protocols governing the placement, maintenance and monitoring of urinary catheters and more generally the lack of prevention and control of urinary tract infections. The incidence of the catheterassociated UTI (CAUTI) can be reduced. To do this, a better catheterassociated UTI control policy must be put in place in our clinic and even having a similar policy in the entire hospital would be better. The reduction of this incidence of CAUTI could be inspired by the standardization of urinary catheterization practices and by bundling interventions $[28,29]$.

The overall antimicrobial resistance of the main isolated bacterial strains was very high regarding amoxicillin-clavulanate, third generation cephalosporin, ciprofloxacin and trimethoprimsulfamethoxazole with resistance rate of $48 \%, 30.4 \%, 48.8 \%$ and $46 \%$ respectively. Individually, resistance of Klebsiella strains to antibiotics was high for amoxicillin clavulanic acid (82.4\%), ciprofloxacin $(73.5 \%)$, cotrimoxazole $(61.8 \%)$ and third generation cephalosporin (41.2\%). Isolated Escherichia coli strains showed equally high antibiotic resistance levels for amoxicillin-clavulanate, ciprofloxacin, trimethoprim-sulfamethoxazole and third generation cephalosporin with $60.6 \%, 57.6 \%, 45.5 \%$ and $42.4 \%$ respectively. Extended-spectrum $\beta$-lactamases (ESBLs)-producing Enterobacteriaceae strains were not listed in this study. However, in a previous study in the same hospital, these ESBLs-producing Enterobacteriaceae were present in $34.7 \%$ of the strains, more than half of the Klebsiella pneumoniae strains produced it and nearly one third for the Escherichia coli strains [17]. On the contrary, lower rates are found in North America and Europe [30]. The acquisition of genes encoding the resistance of Enterobacteriaceae is through multiple mechanisms such as $\beta$ lactamase AMpCs, ESBLs, and carbapénémases [31]. These different resistance genes had not been characterized in our study due to the lack of equipment in our laboratory.

The very high levels of resistance to amoxicillin-clavulanate, ciprofloxacin, trimethoprim-sulfamethoxazole and the thirdgeneration cephalosporin were also reported previously in the same hospital [17] but also in Africa [25,32,33] and at the global level [3]. In our Clinic, this is explained by their very wide use in daily practice, especially in a presumptive and first-line manner during the UTI. For Bader et al. antibiotic resistance among causative Gram-negative Bacilli is increasing and considered to be a challenge for clinicians since there are limited treatment options [2].

Half of the patients in our study (49 cases) received probabilistic antibiotic therapy. In mono-antibiotherapy, the first-line molecule was ceftriaxone and in bi-antibiotic therapy it was amoxicillin-clavulanate and spiramycin. Both ceftriaxone and amoxicillin-clavulanate are most often ineffective depending on the results of antimicrobial resistance.

This high resistance may justify the change of antibiotics used during the empirical treatment of urinary tract infections in the service. To do this, nitrofurantoin, pivmecillinam and fosfomycin trometamol must be made available. Concerning the use of fosfomycin, it should be monitored because increasing resistance to this molecule has begun to appear in some countries especially for ESBLs-Escherichia coli strains and ESBLs-Klebsiella pneumoniae hospital-acquired strains [34]. A policy for a better use of antibiotics should be introduced because of this strong antimicrobial resistance and the fact that some antibiotics are not available. Also, the prescription of antibiotics will have to be framed for their rational use. In addition, facing this significant share of HAUTI, better definitions 
of these infections should also be adopted justifying the antibiotics to be used.

During care taking, $36.7 \%$ of patients died. It is difficult to say exactly whether the deaths recorded were related to urinary tract infection because hospitalized patients often had other morbid associations including HIV infection in more than three-quarters of patients. We think it is necessary to conduct further studies that will identify factors associated with death in these patients.

Given these results, it appears urgent to conduct a prospective study for a better knowledge of the sensitivity of bacterial strains isolated during urinary tract infections in the hospital. This will help define better treatment recommendations for these infections.

One of the limitations of our study lies in its retrospective character which did not allow a better completeness of the data especially on the bacteriological status of the patients. Another limitation of this study is related to the nature of the population studied with a predominance of HIV infected persons who could have introduced some changes the bacterial profile of UTIs.

Despite these limitations, the results of our study are instructive and highlight some measures to be taken to reduce urinary tract infections in our clinic, particularly CAUTI.

\section{Conclusion}

Our study has revealed that in our Clinic, urinary tract infections are dominated by Enterobacteria such as Klebsiella pneumoniae and Escherichia coli. The antimicrobial resistance of these strains is very high, and therefore reduces the possibilities of probabilistic treatment with amoxicillin-clavulanate, ciprofloxacin and the third-generation cephalosporin. However, the classification of these infections in CAUTI and HAUTI is not easy in our context. A better knowledge of the bacterial epidemiology of UTI including their sensitivity to antibiotics is necessary to guide the recommendations for antibiotic therapy of these infections. Also, strategies for the reduction for these UTIs must be implemented, mainly through the coding of UTIs, urinary catheter placement and monitoring protocols, continuous surveillance of urinary tract infections in our clinic and on a larger scale in our hospital. Protocols adapted treatment must also be adopted.

\section{References}

1. Gonzalez CM, Schaeffer AJ (1999) Treatment of urinary tract infection: What's old, what's new, and what works. World J Urol 6: 372-382.

2. Bader MS, Loeb M, Brooks AA (2017) An update on the management of urinary tract infections in the era of antimicrobial resistance. Postgrad Med 2: 242-258.

3. Tandogdu Z, Wagenlehner FME (2016) Global epidemiology of urinary tract infections. Curr Opin Infect Dis 1: 73-79.

4. Laupland KB, Ross T, Pitout JDD, Church DL, Gregson DB (2007) Community-onset urinary tract infections: a population-based assessment. Infection 3: 150-153.

5. Singhal A, Sharma R, Jain M, Vyas L (2014) Hospital and community isolates of uropathogens and their antibiotic sensitivity pattern from a tertiary care hospital in North West India. Ann Med Health Sci Res 1: 51-56.

6. Szász M, Lehotkai N, Kristóf K, Szabó D, Nagy K (2009) Prevalence and antimicrobial resistance of uropathogens in different inpatient wards. Acta Microbiol Immunol Hung 4: 375-387.
7. Tambyah PA, Maki DG (2000) Catheter-Associated urinary tract infection is rarely symptomatic: a prospective study of 1,497 catheterized patients. Arch Intern Med 5: 678-682.

8. Magill SS, Edwards JR, Bamberg W, Beldavs ZG, Dumyati G, et al. (2014) Multistate point-prevalence survey of health care-associated infections. N Engl J Med 13: 1198-1208.

9. Afriyie DK, Gyansa-Lutterodt M, Amponsah SK, Asare G, Wiredu V, et al. (2015) Susceptibility pattern of uropathogens to ciprofloxacin at the Ghana police hospital. Pan Afr Med J: 87.

10. Edoh V, Tia H, Kanga C (2002) Infections urinaires bacteriennes chez les sujets porteurs du virus de l'immuno-deficience humaine (VIH) suivis a l'unite de soins ambulatoires et de conseil (USAC) au CHU de TreichvilleAbidjan. Médecine Afr Noire 10: 436-438.

11. Omoregie R, Eghafona NO (2009) Urinary tract infection among asymptomatic HIV patients in Benin City, Nigeria. Br J Biomed Sci 4 190-193.

12. Bouchillon SK, Badal RE, Hoban DJ, Hawser SP (2013) Antimicrobial susceptibility of inpatient urinary tract isolates of gram-negative bacilli in the United States: results from the study for monitoring antimicrobial resistance trends (SMART) program: 2009-2011. Clin Ther 6: 872-877.

13. Oli AN, Akabueze VB, Ezeudu CE, Eleje GU, Ejiofor OS, et al. (2017) Bacteriology and antibiogram of urinary tract infection among female patients in a tertiary health facility in South Eastern Nigeria. Open Microbiol J: 292-300.

14. Omoregie R, Erebor JO, Ahonkhai I, Isibor JO, Ogefere HO (2008) Observed changes in the prevalence of uropathogens in Benin City, Nigeria. NZJ Med Lab Sci 2: 29-31.

15. Tansarli GS, Athanasiou S, Falagas ME (2013) Evaluation of antimicrobial susceptibility of Enterobacteriaceae causing urinary tract infections in Africa. Antimicrob Agents Chemother 8: 3628-3639.

16. Dia NM, Ka R, Dieng C, Diagne R, Dia ML, et al. (2008) Prevalence of nosocomial infections in a university hospital (Dakar, Senegal). Médecine Mal Infect 5: 270-274

17. Dia ML, Chabouny H, Diagne R (2015) Antibiotic susceptibility pattern of uropathogenic bacterial isolates in a Dakar Senegalese Teaching Hospital. Rev Afr Urol Androl 4.

18. Dao S, Oumar AA, Dembele JP, Noutache JL, Fongoro S, et al. (2007) Clinical and bacteriological profiles of the urinary infections associated the VIH/AIDS in hospital area of Bamako, Mali. Mali Med 1: 10-13.

19. Adeep M, Nima T, Kezang W, Tshokey T (2016) A retrospective analysis of the etiologic agents and antibiotic susceptibility pattern of uropathogens isolated in the Jigme Dorji Wangchuck National Referral Hospital, Thimphu, Bhutan. BMC Res Notes: 54.

20. Khatri B, Basnyat S, Karki A, Poudel A, Shrestha B (2012) Etiology and antimicrobial susceptibility pattern of bacterial pathogens from urinary tract infection. Nepal Med Coll J NMCJ 2: 129-132.

21. Rasamiravaka T, Shaista Sheila HSL, Rakotomavojaona T, Rakoto-Alson AO, Rasamindrakotroka A (2015) Changing profile and increasing antimicrobial resistance of uropathogenic bacteria in Madagascar. Med Mal Infect 5: 173-176.

22. Hooton TM, Scholes D, Stapleton AE, Roberts PL, Winter C, et al. (2000) A prospective study of asymptomatic bacteriuria in sexually active young women. N Engl J Med 14: 992-997.

23. Foxman B (2014) Urinary tract infection syndromes: occurrence, recurrence, bacteriology, risk factors, and disease burden. Infect Dis Clin North Am 1: 1-13.

24. Renuart AJ, Goldfarb DM, Mokomane M, Tawanana EO, Narasimhamurthy M, et al. (2013) Microbiology of urinary tract infections in Gaborone, Botswana. PloS One 3: e57776.

25. Beyene G, Tsegaye W (2011) Bacterial uropathogens in urinary tract infection and antibiotic susceptibility pattern in jimma university specialized hospital, southwest ethiopia. Ethiop J Health Sci 2: 141-146.

26. Uçkay I, Sax H, Gayet-Ageron A, Ruef C, Mühlemann K, et al. (2013) High proportion of healthcare-associated urinary tract infection in the 
Citation: Lakhe NA, Mbaye KD, Sylla K, Dia ML, Badiane NMD, et al. (2018) Urinary Tract Infection Profile at the Clinic of Infectious and Tropical Diseases at Fann University Hospital, Dakar, Senegal. J Antimicrob Agents 4: 174. doi:10.4172/2472-1212.1000174

Page 8 of 8

absence of prior exposure to urinary catheter: a cross-sectional study Antimicrob Resist Infect Control 1: 5.

27. Gardner A, Mitchell B, Beckingham W, Fasugba O (2014) A point prevalence cross-sectional study of healthcare-associated urinary tract infections in six Australian hospitals. BMJ Open 7: e005099.

28. Clarke K, Tong D, Pan Y, Easley KA, Norrick B, et al. (2013) Reduction in catheter-associated urinary tract infections by bundling interventions. Int J Qual Health Care J Int Soc Qual Health Care 1: 43-49.

29. Cartwright A (2018) Reducing catheter-associated urinary tract infections: standardising practice. Br J Nurs Mark Allen Publ 1: 7-12.

30. Hoban DJ, Lascols C, Nicolle LE, Badal R, Bouchillon S, et al. (2012) Antimicrobial susceptibility of Enterobacteriaceae, including molecular characterization of extended-spectrum beta-lactamase-producing species, in urinary tract isolates from hospitalized patients in North America and Europe: results from the SMART study 2009-2010. Diagn Microbiol Infect Dis 1: 62-67.
31. Magiorakos A-P, Srinivasan A, Carey RB, Carmeli Y, Falagas ME, et al. (2012) Multidrug-resistant, extensively drug-resistant and pandrugresistant bacteria: an international expert proposal for interim standard definitions for acquired resistance. Clin Microbiol Infect Off Publ Eur Soc Clin Microbiol Infect Dis 3: 268-281.

32. Dromigny JA, Nabeth P, Claude JDPG (2002) Distribution and susceptibility of bacterial urinary tract infections in Dakar, Senegal. Int J Antimicrob Agents 5: 339-347.

33. Bercion R, Mossoro-Kpinde D, Manirakiza A, Le Faou A (2009) Increasing prevalence of antimicrobial resistance among Enterobacteriaceae uropathogens in Bangui, Central African Republic. J Infect Dev Ctries 3: 187-190.

34. Linsenmeyer K, Strymish J, Weir S, Berg G, Brecher S, et al. (2016) Activity of Fosfomycin against Extended-Spectrum- $\beta$-LactamaseProducing Uropathogens in Patients in the Community and Hospitalized Patients. Antimicrob Agents Chemother 2: 1134-1136. 